\title{
Trapeziometacarpal joint arthritis: A retrospective study of the natural history of symptomatic thumb arthritis
}

Jessica Frankenhoff,' Jeffrey Stromberg, Aimee Riley, Jun He, Prem Madesh, Jonathan Isaacs

Virginia Commonwealth University, United States

Received: September 30, 2019

Accepted: October 30, 2019

Online Published: November 7, 2019

DOI: $10.5430 /$ css.v5n2p11

URL: https://doi.org/10.5430/css.v5n2p11

\begin{abstract}
Objective: Trapeziometacarpal (TM) joint arthritis is a common source of hand pain in patients presenting to the hand surgeon's clinic. Long-term data on the natural history of symptomatic TM arthritis is lacking.

Methods: We identified 251 patients with symptomatic TM arthritis and performed a retrospective chart review which identified treatment modalities (including surgery) and long term outcomes which were assessed via a telephone survey.

Results: We found that of the 251 patients who presented with symptomatic TM arthritis, the 114 patients who had surgery had less pain and disability in the long term than those patients who were treated conservatively with splinting or injection (average pain score 1.8 vs. 3.8). However, the majority of patients did not ultimately undergo surgery.

Conclusions: Although patients fare better from a pain and function standpoint with surgery, surgery is not inevitable.
\end{abstract}

Key Words: Trapeziometacarpal arthritis, Basilar joint, Ligament reconstruction tendon interposition arthroplasty, Natural history

\section{INTRODUCTION}

Trapeziometacarpal (TM) joint arthritis is a common source of hand pain in patients presenting to the hand surgeon's clinic. Though the prevalence of this arthritis increases with age, some patients remain asymptomatic and many other patients report debilitating pain that limits activities of daily living (ADL's). Many conservative options have been described as well as several effective surgical treatments. However, when considering these options, symptomatic patients often inquire if surgical intervention is inevitable, and if so, question the need for "temporizing" conservative management. The question of surgical inevitability is difficult to answer. While the overall favorable predictability of surgical intervention is well known, ${ }^{[1-4]}$ long-term data on the natural history of symptomatic TM arthritis is lacking.

We identified patients seen in our hand division with symptomatic TM arthritis. A retrospective chart review identified treatment modalities (including surgery) and long-term outcomes were assessed via telephone survey.

\section{MethodS}

After obtaining institutional IRB approval a retrospective chart review was performed at our institution querying charts from January, 2003 to January, 2016 for ICD-9 and ICD10 codes for hand arthritis (ICD9 - 715.14, 715.34, 715.94 ICD10 - M18; all M18 derivatives, M19.049). All patients States.

*Correspondence: Jessica Frankenhoff, M.D.; Email: jessica.frankenhoff@vcuhealth.org; Address: Virginia Commonwealth University, United 
had been seen and evaluated by one of four fellowship trained hand surgeons. 914 patients were identified as having hand arthritis. Each chart was audited, and those with symptomatic TM arthritis were included. Those without TM arthritis were excluded from the study, along with patients with a history of previous trauma, rheumatoid arthritis, or gout. 633 were excluded (220 without TM arthritis, 196 with incomplete paper charts, 22 with previous trauma, rheumatoid arthritis or gout, and 225 unwilling to do the phone call survey). A total of 251 patients including 341 thumbs with TM arthritis were contacted and included in the final analysis. 30 patients could not be contacted. Patients seen for bilateral thumb arthritis were recorded as separate encounters. Patients with bilateral thumb arthritis were asked to answer the questionnaire twice, focusing their responses first on only the right thumb, then only the left. The medical charts of the included patients were reviewed to identify age, gender, handedness, presence and duration of symptoms, occupation, radiographic stage of the TM arthritis when available, timing and number of steroid injections, use of joint immobilization, timing of conservative and surgical intervention if performed, symptom improvement, and length of follow-up. All included patients were then contacted by a phone call, for a total of three attempted phone calls on different days, to conduct a five question survey of scripted questions (See appendix). Those willing to provide verbal consent to the survey were included, and those patients unwilling to give consent or those unable to be reached were then excluded from the study. The questions asked in the survey were, in brief: 1) 0-10 pain scale for their thumb pain, 2) outside treatment received including what type, 3) If ADL's were affected by thumb pain, 4) If the patient desired to see a hand surgeon again in regards to their thumb pain, 5) Current splint use for thumb pain.

\subsection{Data description}

Eaton grade (Supplemental Table S1) was classified as two groups, mild (I, II) vs. advanced (III, IV). Intervention was categorized as three groups: injection alone, injection and splinting, and splinting alone.

\subsection{Statistical method}

The frequency and percentage of Eaton grade and interventions between patients (reported per symptomatic thumb) who agreed to surgery and those who did not have surgery were reported. A $t$-test was used to test the difference of mean on age between surgery and non-surgery groups. Chisquare test was used to test the association between Eaton grade, sex or intervention in surgery/non-surgery groups. A logistic regression model was used to assess odds ratios.

To estimate the probability of a patient consenting to surgery after first having non-surgical intervention treatment (injection alone, injection and splinting, or splinting alone), a
Kaplan-Meier plot was used. The time length was defined as the period from first having non-surgical treatment until surgical treatment. The end date of study was the day that participants received their survey phone call. If there was no surgery, censored time was defined as the time between the first non-surgical treatment and the end date of the study. Cox's proportional hazard model was used to evaluate the effect of interventions on the time to having surgery.

A $t$-test was used to test the differences of mean pain scores between surgery and non-surgery groups. The frequency and percentage of the desire to return to the hand surgeon for the surgery and nonsurgical groups were calculated separately. A logistic regression model was utilized to test the percentage of patients desiring a re-visit with a hand surgeon between those two groups. Logistic regression models were also used to assess whether pain was a risk factor leading to participants wanting to go back to see their hand surgeon. The odds ratio was used to explain the association between dependent variables and the desire to visit a hand surgeon again. The analysis was similarly utilized to assess TM arthritis affecting ADLs.

All statistical analyses were conducted by using SAS version 9.4 (TS1M3).

\section{RESULTS}

Eaton grade, non-surgical intervention, and age at diagnosis were all associated with having surgery. Gender was not associated with having surgery (see Table 1). 79 out of 212 patients (37.3\%) with advanced Eaton grade (III \& IV) arthritis had surgery and 25 out of 97 patients (25.8\%) with mild Eaton grade (I \& II) arthritis had surgery. Compared to mild Eaton grade, patients with advanced Eaton grade were more likely to have surgery $(\mathrm{OR}=1.7,95 \% \mathrm{CI}=1.0-2.9)$. Regarding non-surgical intervention, 43 out 154 (27.9\%) patients in the injection only group had surgery; 15 out of 18 (83.3\%) patients in the injection and splinting group had surgery; and 9 out $39(23.1 \%)$ patients in the splinting group had surgery. The probability of patients eventually having surgery to treat TM arthritis increased slightly every year for 3 years from $23 \%$ in year one to $29 \%$ by year three following initial presentation to a hand surgeon. Compared to the splinting only group, the injection only group was 1.3 times $(95 \% \mathrm{CI}=$ 0.6-2.9) more likely to have surgery and the injection and splinting group was 16.7 times $(95 \% \mathrm{CI}=3.9-70.8)$ more likely to have surgery than the splinting only group. The patients who agreed to have surgery were younger age (60 \pm 8 years) than the patients who did not have surgery ( $63 \pm 11$ years). The mean time period from initial visit to the phone call was 50.5 months $(S D=28.8)$. The mean time period from presentation to surgery for patients who had surgery was 36.7 months $(S D=29.7)$. 
Table 1. Demographic table between surgery and non-surgery group

\begin{tabular}{|c|c|c|c|c|}
\hline & \multirow{3}{*}{$\mathbf{N}(\%)$} & \multicolumn{2}{|c|}{ Surgery } & \multirow{3}{*}{$p$-value } \\
\hline & & No & Yes & \\
\hline & & $229(67.2)$ & $112(32.8)$ & \\
\hline Eaton grade & & & & $.047^{*}$ \\
\hline Advanced (III \& IV) & $212(68.6)$ & $133(62.7)$ & $79(37.3)$ & \\
\hline Mild (I \& II) & $97(31.4)$ & $72(74.2)$ & $25(25.8)$ & \\
\hline Intervention & & & & $<.05^{*}$ \\
\hline Injection & $154(73.0)$ & $111(72.1)$ & $43(27.9)$ & \\
\hline Injection \& Splinting & $18(8.5)$ & $3(16.7)$ & $15(83.3)$ & \\
\hline Splinting & $39(18.5)$ & $30(76.9)$ & $9(23.1)$ & \\
\hline Sex & & & & .63 \\
\hline Male & $65(19.1)$ & $42(64.6)$ & $23(35.4)$ & \\
\hline Female & $276(80.9)$ & $187(67.8)$ & $89(32.2)$ & \\
\hline Age at diagnosis $($ Mean $\pm S D)$ & 341 & $63 \pm 11$ & $60 \pm 8$ & $.033^{*}$ \\
\hline
\end{tabular}

Note. $S D=$ standard deviation; $t$-test was performed for continuous variable and chi-square test was for categorical variables; ${ }^{*} p<.05$

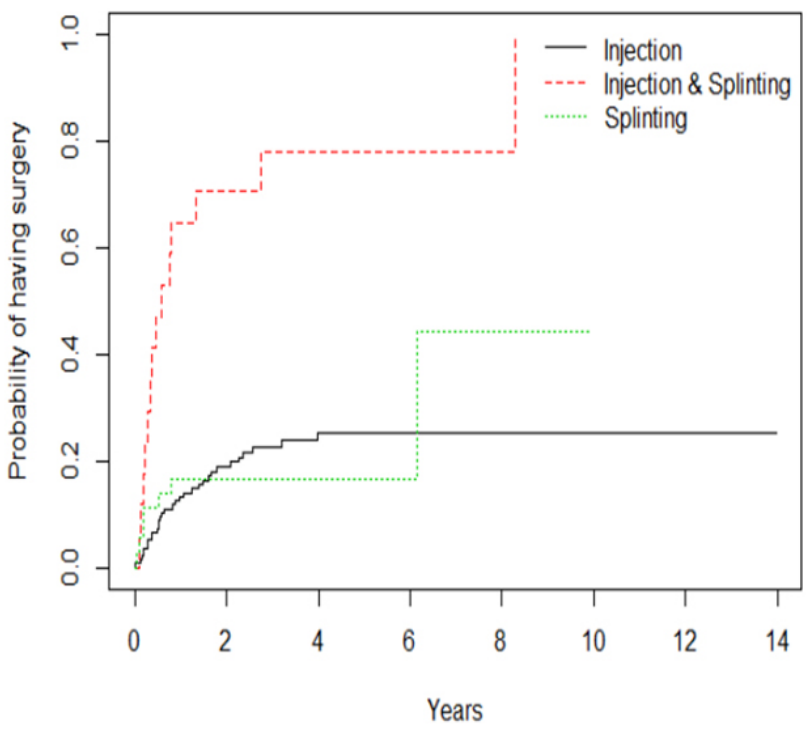

Figure 1. Kaplan-Meier plot for probability of having surgery by intervention groups

The Kaplan-Meier plot showed that patients who had been treated with injection and splinting group (red curve) had the highest probability of having surgery verses the injection only group (black curve) or splinting only group (green curve) (see Figure 1). The proportional hazards assumption was checked. The result of hazard modeling showed that injection and splinting intervention group had a higher hazard rate of having surgery in the future than the splinting only group (Hazard ratio $[\mathrm{HR}]=6.85, p<.05$ ); the injection intervention group had the same hazard rate of having future surgery as the splinting only group $(\mathrm{HR}=1.12, p=.79)$ (see Figure 2).

The non-surgical patients had an average pain score of 3.8 $(S D=2.9)$ and those patients who had previously had surgery

Published by Sciedu Press had an average pain score of $1.8(S D=2.5)(p<.01)$. The thumbs without surgery had statistically higher pain scores than those who had surgery.

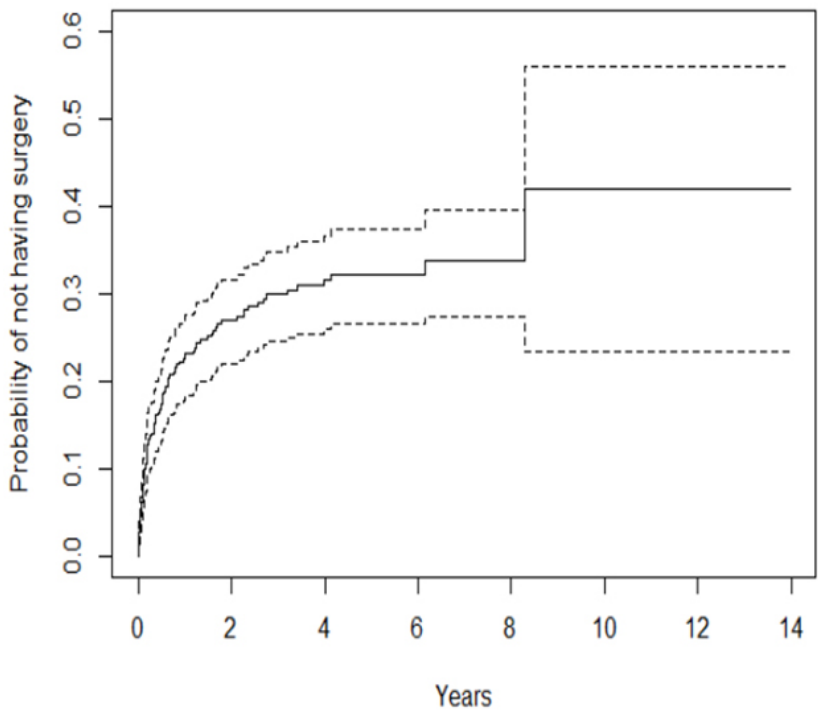

Figure 2. Kaplan-Meier plot for probability of having surgery based on time from presentation

The overall percentage of participants that desired to visit the hand surgeon again was $39.2 \%$ (98 out of 250 participants). There were 75 out of 156 participants $(48.1 \%)$ that wanted to visit a hand surgeon in the non-surgical group and 23 out of 94 participants (24.5\%) in the surgical group.

There were 121 participants (48.4\%) that had affected ADL's. In the non-surgical group, $85(45.5 \%)$ of the participants had affected ADL's versus 36 (38.3\%) in the surgical group. When each thumb was treated as an individual observation, the overall percentage of having affected ADL's was $44.1 \%$ 
( $n=150) .52 .4 \%$ (120 out of 229 thumbs) of non-surgically treated thumbs adversely affected ADL's and 27.0\% (30 out of 111 thumbs) of surgically treated thumbs had this complaint.

The second logistic regression model on hindered ADL's showed that the non-surgical group was more likely to have affected ADL's than surgical group $(p<.01, \mathrm{OR}=3.0,95 \%$ $\mathrm{CI}=1.8-4.9)$. Pain was also a risk factor for having difficulty with ADL's $(p<.01)$. For both groups combined, every 1 point pain increased correlated with an increased likelihood of difficulty with ADL's $(\mathrm{OR}=1.9 ; 95 \% \mathrm{CI}=1.6-2.1)$.

\section{Discussion}

The patients who had surgery did so at an average of 3 years after presentation, implying that patients had surgery secondary to chronic pain, rather than a high intensity of pain at the time of their initial presentation. Regardless of nonsurgical interventions, many patients not opting for surgery continued to have symptoms and more pain than the operative group.

One small study by Day et al. prospectively evaluated the outcome of a single TM injection followed by three weeks of splinting, concluding that long-term relief was primarily provided to those with Eaton Stage 1 arthritis. ${ }^{[5]}$ Their follow-up was a mean of 25 months, indicating that probability of longer-term relief is unknown. Multiple additional studies have investigated surgical treatment options, comparing satisfaction, grip and pinch strength, and risk of complications. ${ }^{[6-9]}$ Yet even more studies have investigated the progression of generalized arthritis of the hand. ${ }^{[9-12]}$ These studies however, are population based or based on radiographic evidence of arthritis alone and do not necessarily represent the types of symptomatic patients presenting to hand surgeons. ${ }^{[13]}$

Two prospective studies have assessed both the change in clinical symptoms and radiographic severity of patients with hand arthritis over time. Botha-Scheeper et al. demonstrated that $4.9 \%$ of TM arthritis advanced radiographically over a period of two years, while the clinical course varied significantly. In their study, $35 \%$ reported improvement in symptoms over the 2 year span, while $50 \%$ reported worsening pain and disability. ${ }^{[9]}$ Their patient population was similar with respect to age at diagnosis and the method of pain measurement (self-reported). However, the studies differed in that Botha-Scheeper et al. asked about generalized hand pain in the interphalangeal joints, not just the thumb, and our mean follow-up was more than double, at 4.2 years. Bijesterbosh et al. prospectively followed patients with hand arthritis, but not specifically TM arthritis, for a span of 6 years, and noted that reported pain was not related to radiographic progression of arthritis. ${ }^{[10]}$

Berggren et al. published a study similar in concept to ours in that they exclusively investigated the natural history of TM arthritis in 33 patients who were symptomatic enough that they were awaiting surgical intervention. Conservative treatment with splinting and education on ADL modification decreased the need for surgical intervention in most patients. Sixty-four percent of these patients no longer desired surgical intervention after 7 years of conservative management. ${ }^{[14]}$ This study, however, had a much smaller patient cohort. At the time, the potential benefits of surgery were not as well established which may have affected both physician and patient enthusiasm for this treatment course. ${ }^{[15]}$ Additionally, the population studied had limited medical access (longer wait time for elective hand surgery) which suggests possible socioeconomic barriers to surgical treatment and rehabilitation.

Our study confirmed the generally accepted benefits of surgery since those from the surgical group had less pain, less difficulty with ADLs, and were less likely to want to see a hand surgeon again compared with those in the non-surgical group. However, we were surprised by the persistence of pain and the still relatively high percentage of patients desiring further hand surgeon evaluation in the surgical group. This may have been related to misinterpretation of our questionnaire which may not have adequately specified our interest in thumb pain and some of these patients may have had unrelated hand pathology.

Though increased radiographic severity did correlate with having surgery, somewhat counter-intuitively, younger patients were also more likely to undergo surgery. Older patients are often retired and potentially have less demand on their hands. Additionally, those who had injections with or without splinting were more likely to undergo surgery than those treated with splinting alone. Patients who acquiesced to an injection were perhaps more desperate for relief or, conversely just more open to invasive procedures (such as surgery) than those who only opted for splint treatment. However, we were unable to extrapolate meaningful pain scores or patient attitudes towards different treatment modalities at time of initial presentation from our chart review.

In our effort to ensure maximum subject participation, we minimized the phone questionnaire to only five questions. This approach limited the information we could collect and allowed for some ambiguity in the patients interpretation of our inquiries. This may have led to the unexpectedly 
high numbers of surgically treated patients reporting difficulties with ADLs and desire to be evaluated again by a hand surgeon. We did not investigate other factors such as co-morbidities or depression that may lead to perceived disabilities unrelated to their TM arthritis. Perceived disability due to TM arthrosis correlates with depression and ineffective coping skills. ${ }^{[16]}$ Recall bias is always a weakness in this type of survey study.

In conclusion, although patients presenting with symptomatic TM arthritis who have surgery are more likely to have less pain and disability in the long term than those patients who are treated conservatively, surgery is not inevitable.

\section{STATEMENT OF FUNDING}

This research received no specific grant from any funding agency in the public, commercial, or not-for-profit sectors.

\section{STATEMENT OF INFORMED CONSENT}

Informed consent was obtained from all individual participants included in the study.

\section{Statement of Human and Animal RighTS}

All procedures followed were in accordance with the ethical standards of the responsible committee on human experimentation (institutional and national) and with the Helsinki Declaration of 1975, as revised in 2008. ${ }^{[5]}$ Informed consent was obtained from all patients for being included in the study.

\section{IRB}

The IRB was obtained from our institution.

\section{Conflicts of InTERest Disclosure}

The authors declare they have no conflicts of interest.

\section{REFERENCES}

[1] Gillis J, Calder K, Williams J. Review of thumb carpometacarpal arthritis classification, treatment and outcomes. CJPS. 2001; 19(4): 134-138. PMid: 23204884. https : //doi.org/10.1177/229255 031101900409

[2] Vinycomb T, Crock J. Trapeziectomy with ligament reconstruction and tendon interpostion: A minimum 10 year follow-up. Hand Surgery. 2013; 18(3): 365-368. PMid: 24156579. https://doi. org/10.1142/S0218810413500408

[3] Rhee PC, Paul A, Carlsen B, et al. Outcomes of surgical management for thumb basilar arthritis in patients 55 years of age and younger. Hand online. 2018. PMid: 29619885. https ://doi .org/10.117 $7 / 1558944718769378$

[4] Matulio KS, Ilyas A, Thoder JJ. CMC arthroplasty of the thumb: A review. Hand. 2007; 2(4): 232-239. PMid: 18780059. https: //doi.org/10.1007/s11552-007-9068-9

[5] Day CS, Gelberman R, Patel AA, et al. Basal Joint Arthritis of the Thumb: a prospective trial of steroid injection and splinting. JHS. 2004; 29(2): 247-251. PMid: 15043897. https ://doi.org/10.1 016/j.jhsa.2003.12.002

[6] Aita MA, Alves RS, Longuino LF, et al. Measurement of Quality of like among patients undergoing arthroplasty of the thumb to treat CMC arthritis. RBO. 2016; 51(4): 431-436. PMid: 27517022. https://doi.org/10.1016/j.rboe.2016.06.003

[7] Spekreijse K, Steyerberg E, Tsehaie J, et al. Predicting outcome after surgery for Carpometacarpal osteoarthritis, a prospective study. Hand 2016; 11(1): 1S-2S. https://doi.org/10.1177/155894 $4716660555 \mathrm{~b}$

[8] Raven EEJ, Kerkhoffs GM, Rutten S, et al. Long term results of surgical intervention for osteoarthritis of the trapeziometacarpal joint. Int. Orthop. 2007 Aug; 31(4): 547-554. PMid: 17021835. https ://doi.org/10.1007/s00264-006-0217-5
[9] Botha-Scheepers S, Riyazi N, Watt I, et al. Progression of Hand Osteoarthritis over 2 years: a clinical and radiological follow-up study. ARD. 2009; 15(8): 1260-1264. PMid: 18728047. https : //doi.org/10.1136/ard.2008.087981

[10] Bijsterbosch J, Watt I, Meulenbelt I, et al. Clinical And radiographic disease course of hand osteoarthritis and determinants of outcome after 6 years. ARD. 2011; 70: 68-73. PMid: 20736393. https://doi.org/10.1136/ard.2010.133017

[11] Haugen I, Slatkowsky-Christensen B, Boyesen, P, et al. Crosssectional and Longitudinal associations between radiographic features and measures of pain and physical function in hand osteoarthritis. OARSI. 2013; 21(9): 1191-1198. PMid: 23973130. https : //doi.org/10.1016/j.joca.2013.04.004

[12] Paradowski PT, Lohmander LS, Englund M. Natural history of radiographic features of hand osteoarthritis over 10 years. OARSI. 2010; 18(7): 917-922. PMid: 20417289. https://doi.org/10.1016/j joca. 2010.04 .008

[13] Frouzakis R, Herren DB, Marks M. Evaluation of expectations and expectation fulfillment in patients treated for trapeziometacarpal osteoarthritis. JHS. 2015; 40(3): 483-490. PMid: 25617218. https : //doi.org/10.1016/j.jhsa.2014.10.066

[14] Berggren M, Joost-Davidsson A, Lindstrand J, et al. Reduction in the need for operation after conservative treatment of osteoarthritis of the first carpometacarpal joint: a seven year prospective study. Scand J Plast Reconstr Surg Hand Surg. 2001; 35(4): 415-417. PMid: 11878178. https://doi.org/10.1080/028443101317149381

[15] Burton RI, Pellegrini VD Jr. Surgical management of basal joint arthritis of the thumb. Part II. Ligament reconstruction with tendon interposition arthroplasty. JHS. 1986; 11A: 324-332. https : //doi.org/10.1016/S0363-5023(86)80137-X

[16] Lozano-Calderon SA, Souer JA, Jupiter JB, et al. Psychological differences between patients that elect operative or nonoperative treatment for trapeziometacarpal joint arthrosis. Hand. 2008; 3: 271-275. PMid: 18780109. https://doi.org/10.1007/s11552-008-9098-y 